\title{
Who has the authority to revoke an approved protocol?
}

\begin{abstract}
$\mathrm{t}$ was the first time that John Callahan had been to an IACUC meeting, but there he was, telling the committee that he was revoking the approval of a previously approved protocol. Callahan was the dean of the Graduate School of Biomedical Sciences at Great Eastern University, and through a casual lunchtime conversation he learned that cardiac resuscitation and tracheal cutdown demonstrations, using terminally anesthetized pigs, had been approved by the IACUC and were scheduled to begin in a week. Callahan told the committee that he strongly supported animal use for biomedical research and in some cases for teaching, but he reminded the IACUC that the school had just installed a human cardiothoracic simulation laboratory that would replace the use of animals for the cardiothoracic teaching procedures that were previously approved by the committee. He added that using the pigs would be a waste of animal lives, could draw poor publicity to the school, and put the value of the new laboratory into question. Speaking for the committee, the IACUC chair told Callahan that the committee was fully
\end{abstract}

aware of the new lab and supported its use; however, the lab just opened and until the faculty could be taught how to use the new equipment, which would take at least a few weeks' time, the committee was comfortable allowing a final use of pigs as part of the medical school's teaching curriculum.

Callahan said he was sorry, but the medical school would just have to be patient and wait the short time until the simulation lab was up and running. Then one of the IACUC members said, "John, who gave you the authority to revoke an IACUC approval?"

"I gave myself the authority," said Callahan. "I looked at the PHS Policy and the Animal Welfare Act regulations and both say that applications approved by the IACUC may be subject to further review and approval by officials of the institution. ${ }^{1,2}$ And since I'm an official of the institution, I have the authority to revoke an approval."

"Maybe or maybe not," said the IACUC member. "I'm the assistant dean for diversity at the medical school. Does that title give me the authority to revoke an IACUC approval?
Can the director of the library revoke an IACUC approval? With all due respect John, your position at the graduate school has almost nothing to do with the IACUC's approval of an activity for the medical school and I don't think you have the authority to revoke an approval."

How would your IACUC address this problem? Which officials of an institution do have the authority to revoke an IACUC approval?

\section{Jerald Silverman $\bowtie$ \\ University of Massachusetts Medical School, Worcester, MA, USA. \\ $\bigotimes_{\text {e-mail: Jerald.Silverman@umassmed.edu }}$}

Published online: 24 April 2020 https://doi.org/10.1038/s41684-020-0527-Z

References

1. Public Health Service. PHS Policy on Humane Care and Use of Laboratory Animals. (U.S. Department of Health and Human Services, National Institutes of Health, Bethesda, MD, 2015).

2. Animal Welfare Act. Public Law 89-544, 1966, as amended (P.L. 91-579, P.L. 94-279, and P.L. 99-198), 7 U.S.C. 2131 et seq. Implementing regulations are published in the Code of Federal Regulations (CFR), Title 9, Chapter 1, Subchapter A, Parts 1, 2, and 3,

\section{Rules vs. roles?}

T his scenario consists of two distinct issues. The first issue concerns the roles of the IACUC to review and approve, require modifications in (to secure approval), or withhold approval on behalf of the institution ${ }^{1}$. In order to fulfil its roles, the members of the IACUC need to use their expertise to balance the needs of the ongoing research project with the capabilities of the newly installed human cardiothoracic simulation laboratory.

Although Callahan is new to the committee, he should be provided with the minutes and discussion of the IACUC review of this project. There may have already been a discussion about the project's ongoing use of pigs and the possibility of using the sim lab to replace live animals. ${ }^{3}$ For whatever reason(s), the IACUC during its deliberation found that the continued use of the animals was justified. Since the sim lab is a new training device, it may take several months for the students to learn how to use it effectively. Also, the simulation lab may not be applicable to every scenario required to appropriately teach the students.

The second issue involves who has authority to revoke an IACUC decision. Was Callahan named as the Institutional Official listed on the institution's Assurance? If not, he has no authority to revoke a decision that has been made by a duly appointed IACUC ${ }^{1,2}$. However, he does have every right to question any protocol that deviates from its IACUC approval. It seems that Callahan is trying to apply the idea of the replacement alternative $\mathrm{e}^{3}$ - while commendable, this just may not be realistic currently.

The IACUC should review its policies for continuing review to decide if this particular protocol needs to be revisited more frequently to ensure that the requirement for use of animal models is still necessary.
Regina Correa-Murphy ${ }^{\square}$

West Palm Beach Veterans Affairs Medical Center, West Palm Beach, FL, USA.

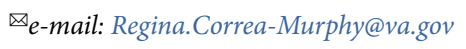

Published online: 24 April 2020 https://doi.org/10.1038/s41684-020-0528-y

References

1. Public Health Service. PHS Policy on Humane Care and Use of Laboratory Animals. (U.S. Department of Health and Human Services, National Institutes of Health, Bethesda, MD, 2015).

2. Animal Welfare Act. Public Law 89-544, 1966, as amended (P.L. 91-579, P.L. 94-279, and P.L. 99-198), 7 U.S.C. 2131 et seq Implementing regulations are published in the Code of Federal Regulations (CFR), Title 9, Chapter 1, Subchapter A, Parts 1,2 , and 3 .

3. Russell, W. M. S, \& Burch, R. L. The principles of humane experimental technique. (Methuen, London 1959)

\section{Disclaimer}

The views expressed in this article are those of the author and do not necessarily reflect the position or policy of the Department of Veterans Affairs or the United States government. 